\title{
Comparative study between natural and synthetic Hydroxyapatite: structural, morphological and bioactivity properties
}

\author{
Paola Andrea Forero Sossa ${ }^{1,2}$, Belarmino Segura Giraldo ${ }^{1,2}$, \\ Beatriz Clemencia Galviz Garcia ${ }^{1}$, Elisabeth Restrepo Parra ${ }^{1,3}$, \\ Pedro Jose Arango Arango ${ }^{1}$
}

\footnotetext{
${ }^{1}$ Laboratorio de Física del Plasma - Universidad Nacional de Colombia Sede Manizales, Laboratorio de Física del Plasma, Campus La Nubia, Manizales, Caldas,Colombia.

${ }^{2}$ Grupo de investigación en Física y Matemáticas con énfasis en la formación de ingenieros - Universidad Autónoma de Manizales, Carrera 19 A, Manizales, Caldas, Colombia.

${ }^{3}$ PCM Computacional Aplicaciones - Universidad Nacional de Colombia Sede Manizales, Laboratorio de Física del Plasma, Campus La Nubia, Manizales, Caldas,Colombia.

e-mail: paaforeroso@unal.edu.co, bsegurag@unal.edu.co, bcgalvizg@unal.edu.co, erestrepop@unal.edu.co, pjarangoa@unal.edu.co
}

\begin{abstract}
In this work, a study of hydroxyapatite (HAp) powders obtained using both, porcine bones and chemical precursors was carried put. In the case of HAp obtained by means of porcine bones, physical processes as cooking, washing and milling were developed, for removing the organic material from the bones; after that, the powders were submitted to a thermal treatment at $800{ }^{\circ} \mathrm{C}$, during $12 \mathrm{~h}$. This procedure was carried out without adding chemical alkalines that are harmful for the environment and the human health. On the other hand, HAp powders were also synthetized using the chemical precipitation method widely reported, showing successful results. Moreover, both kind of powders were characterized using x ray diffraction, Fourier transformer infrared spectroscopy, scanning electron microscopy and energy dispersive spectroscopy. Furthermore, the bioactivity of the materials was determined using the simulated biological fluid (SBF) method. Results showed that the natural HAp exhibited better crystallographic properties. Moreover, according to these results, HAp obtained from porcine bones contains traces of elements as $\mathrm{Na}$ and $\mathrm{Mg}$ that are favorable for the bioactivity, according to the materials behavior when they are immersed in SBF.
\end{abstract}

Keywords: Hydroxyapatite, porcine bones, chemical precipitation, simulated biological fluid.

\section{INTRODUCTION}

Hydroxyapatite is considered as a biomaterial widely employed in many health applications. It is specially used as a source of calcium to produce toothpaste and as an important compound to repair bones. Because of its chemical properties, hydroxyapatite exhibits a great bioactivity and is highly compatible with the adjacent bone and teeth in living beings. Hydroxyapatite is a calcium phosphate ceramic with a high biocompatibility and is nontoxic, being an integral part of bone and teeth tissue in [1]. When HAp is in contact with the osseous tissue, it promotes the bone growth toward the implant [2,3]. HAp with chemical formula Ca10(PO4)6(OH)2, has been widely studied since 1926 by Jong et al [4]. They found a relationship between the osseous mineral and HAp [4]; afterwards, Posner et al [5-7] carried out great advances, especially regarding the crystallographic structure identification of HAp obtained by means of chemical precipitation. Currently, there is a lot of research not only about the production of good quality HAp exhibiting suitable biocompatible properties, but also in searching economical and not polluting production methods [8,9]. The most used methods for obtaining HAp are: the hydrothermal [10,11], chemical precipitation [12-14], biogenic sources $[8,15]$, among others. The last two methods represent the $30 \%$ of the reports in indexed journals from 1999 [9].

The advantages of chemical precipitation and biogenic sources compared with others are: their low cost, few sub-products, the possibility of controlling the particle size and easy availability [9,15]. Particularly, biogenic sources exhibit as advantages, the production of materials with high crystallinity and friendly with the environment, since they represent sources without any type of contamination [8,9]; furthermore, the bio- 
genic sources allow the material to keep the native architecture of the animal osseous tissue, producing apatite that, under suitable conditions, behaves as an osteoconductive material [16].

Chemical precursor methods to obtain HAp, exhibit several advantages as high crystallinity, purity and suitable $\mathrm{Ca} / \mathrm{P}$ ratio [9]; nevertheless, the lack of $\mathrm{Fe}^{2+}, \mathrm{Mg}^{2+}, \mathrm{Si}^{2+}, \mathrm{Na}^{+}, \mathrm{F}^{-}$ions, that is a specific characteristic of the osseous apatite, is the main disadvantage of HAp produced by this method, compared to that obtained using biogenic source methods [3,17]. Furthermore, some of the most biogenic sources used and reported in the literature are: egg shells [15], animal bones [18-22], fish spines [8], among others. On the other hand, one of the most used methods for studying the bioactivity was reported by Kokubo et al [23]. In this method, the material is immersed in a simulated biological fluid (SBF) that contains the same ionic concentration than the human blood plasma. This characteristic is required, because when the material is implanted into the human body, crystals of apatite, like the bone, are formed on the surface; then, the material can be joined to the bone using the apatite layer. This in vivo formation of apatite can be reproduced on the material surface, when it is immersed in a SBF solution [24]; hence, in an initial approach, the degree of bioactivity can be obtained. In the study performed by Hesaraki et al. [25], HAp was produced using the chemical precipitation method; after that, samples were submerged in a SBF, to obtain carbonated HAp (CHAp). It was determined the behavior of this CHAp, in mesenchymal mother cells (MSC), obtained from mice; in contrast, our work includes, not only the study of synthetic HAp, but also the analysis of biogenic HAp; it is an important advantage, since the natural HAp is more economic and the main raw material is highly accessible. The surface layer of apatite is normally characterized using techniques as $\mathrm{x}$ ray diffraction (XRD) and scanning electron microscopy (SEM); XRD allows to identify the crystalline phases of this calcium phosphate. Similarly, the SEM micrographs allow us to determine the morphology and the growth of apatite; nevertheless, few reports of Fourier transformed infrared spectroscopy (FTIR) analysis using the attenuated total reflectance (ATR) can be found in the literature. The main objective of this analysis is to determine functional groups and vibrational modes of the material molecules; for this reason, this is a suitable method to identify the apatite.

Currently, some researches focused on HAp obtained from porcine bones coincide in using sodium hydroxide $[\mathrm{NaOH}]$, to take away the organic part from the bones; nevertheless, $\mathrm{NaOH}$ is a highly alkaline chemic that generates important quantities of hazardous waste. It makes that this chemical compound may be used in an especial way, generating an increase in the method cost and environmental damage [19,20,22,26]; moreover, according to the literature, all the works reporting HAp extracted from animal bones use any derivate of NaHO. For this reason, it is important to investigate about methods to obtain HAp from biogenic sources trying to protect the environment, avoiding the use of chemical contaminants.

This research presents a method to extract HAp from porcine bones, including physical processes without using hazardous chemical reagents; furthermore, the material obtained will be compared with HAp powders obtained from the chemical precipitation method, to determine the efficiency of the proposed method. Finally, materials obtained were characterized by the x-ray diffraction (XRD), Fourier transformed infrared spectroscopy (FTIR), scanning electron microscopy (SEM) and energy dispersive spectroscopy (EDS); similarly, the bioactivity of the obtained materials was analyzed using the simulated biological fluid (SBF) technique, applying the Kokubo method [27]; afterwards, the materials were again characterized using FTIR and SEM.

\section{EXPERIMENTAL DETAILS}

\subsection{Synthesis of Natural Hydroxyapatite}

Powders of natural HAp were obtained from femur of pig bones with sacrifice age of around six months. Initially, the bone is submitted to a deproteinisation process. It consists in eliminating the organic material from the bone. First, a conventional cooking to remove great part of the lipid membrane and tissue was employed; after that, the cooked bones were gridding to extract the medulla; then, the product is exposed to microwaves radiation at a power of $700 \mathrm{~W}$ by 30 minutes, in order to extract the remained lipids of the bones; finally, the bone spicules were washed using oxalic acid to promote the formation of carbonated hydroxyapatite. The well cleaned bone spicules without any organic material were milled using a ball mill, until a powder with particle size lower than $38 \mu \mathrm{m}$ was obtained. The powder was submitted to a thermal treatment at $800^{\circ} \mathrm{C}$ during $24 \mathrm{~h}$, in order to promote the crystalline structure of the HAp [21]. The process to obtain the natural HAp is presented in figure 1 . 


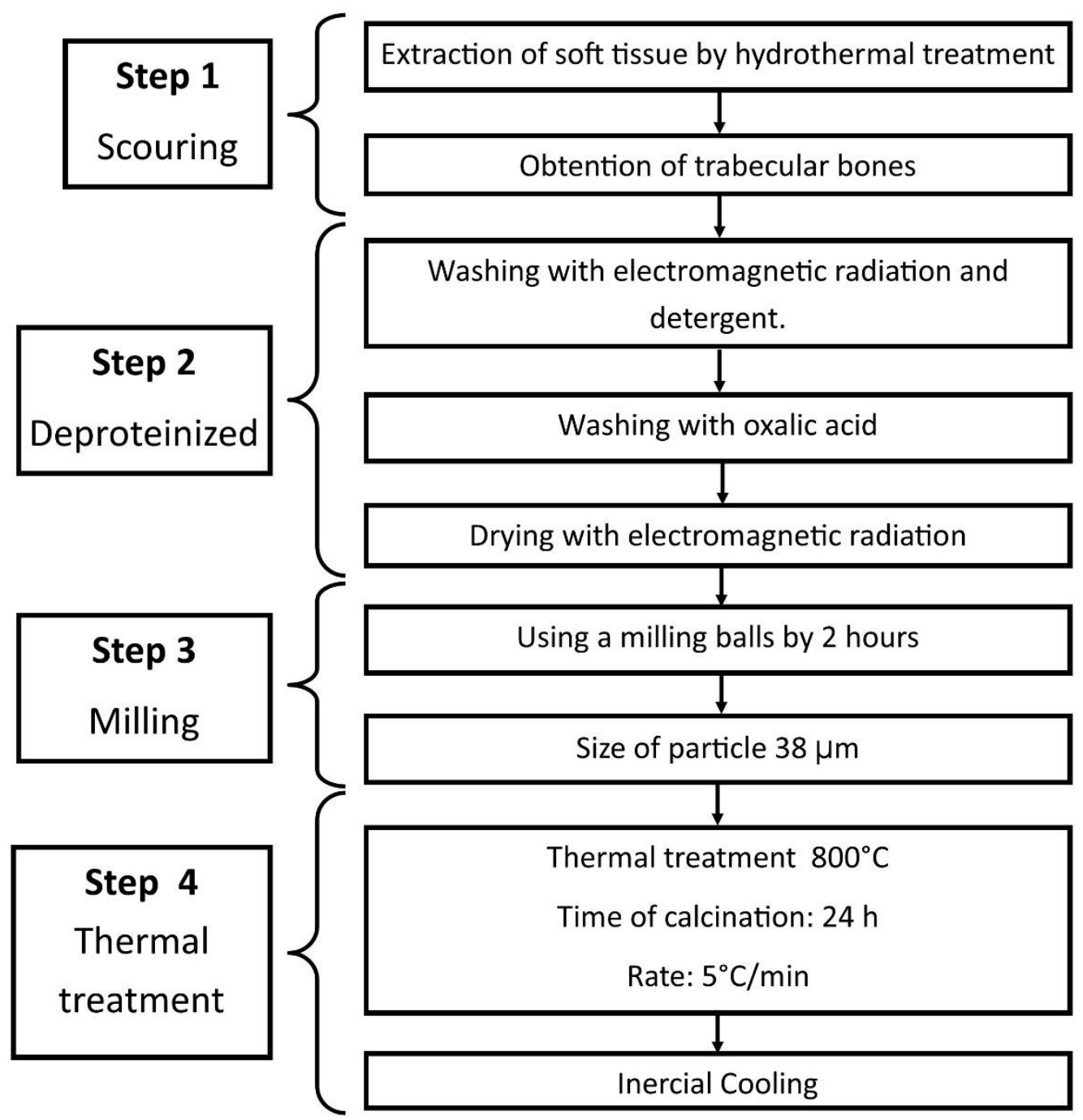

Figure 1: Scheme of the methodology used for obtaining HAp from pig bones as a biogenic source (natural method).

\subsection{Synthesis of Hydroxyapatite by chemical precipitation}

Synthetic powders of HAp were obtained from the next chemical precursors: Calcium nitrate 4-hydrate $\left(\mathrm{Ca}\left(\mathrm{NO}_{3}\right)_{2} \cdot 4 \mathrm{H}_{2} \mathrm{O}\right)$ at $98 \%$ of purity (Panreac) and ammonium di-hydrogen phosphate $\left(\left(\mathrm{NH}_{4}\right) \mathrm{H}_{2} \mathrm{PO}_{4}\right)$ at $99 \%$ of purity (Panreac). The solution of $\mathrm{Ca}\left(\mathrm{NO}_{3}\right)_{2} \cdot 4 \mathrm{H}_{2} \mathrm{O}$ was used at a concentration of 1 mol, while the solution of $\left(\left(\mathrm{NH}_{4}\right) \mathrm{H}_{2} \mathrm{PO}_{4}\right)$ was employed at $0.6 \mathrm{~mol}$. The nitrate calcium was used as a base solution, adding to it the monobasic phosphate solution drop by drop. With this procedure, $\mathrm{pH}$ remained lower than 8 during the reaction by adding ammonia $\left(\mathrm{NH}_{4}\right)$; similarly, the temperature reaction was controlled, keeping it constant at $37^{\circ} \mathrm{C} \pm 3^{\circ} \mathrm{C}$; afterwards, the magnetic shaking was carried out during 3 hours and the aging was maintained during 64 hours. The precipitation obtained was strongly washed in order to eliminate the excess of ammonia added during the reaction. Finally, the plaster was filtered by using filter paper. The material was dried at $80^{\circ} \mathrm{C}$ during $12 \mathrm{~h}$ and after that, a milling procedure, using an agate mortar, was carried out. The solubility of the synthetic calcium phosphates depending on the $\mathrm{pH}$ was determined; for this reason, at $\mathrm{pH} \geq 8, \mathrm{HAp}$ crystals are formed; then, a further thermal treatment is required, in order to promote the formation and growth of HAp [9], [14]. The process for obtaining synthetic HAp is described in figure 2. 


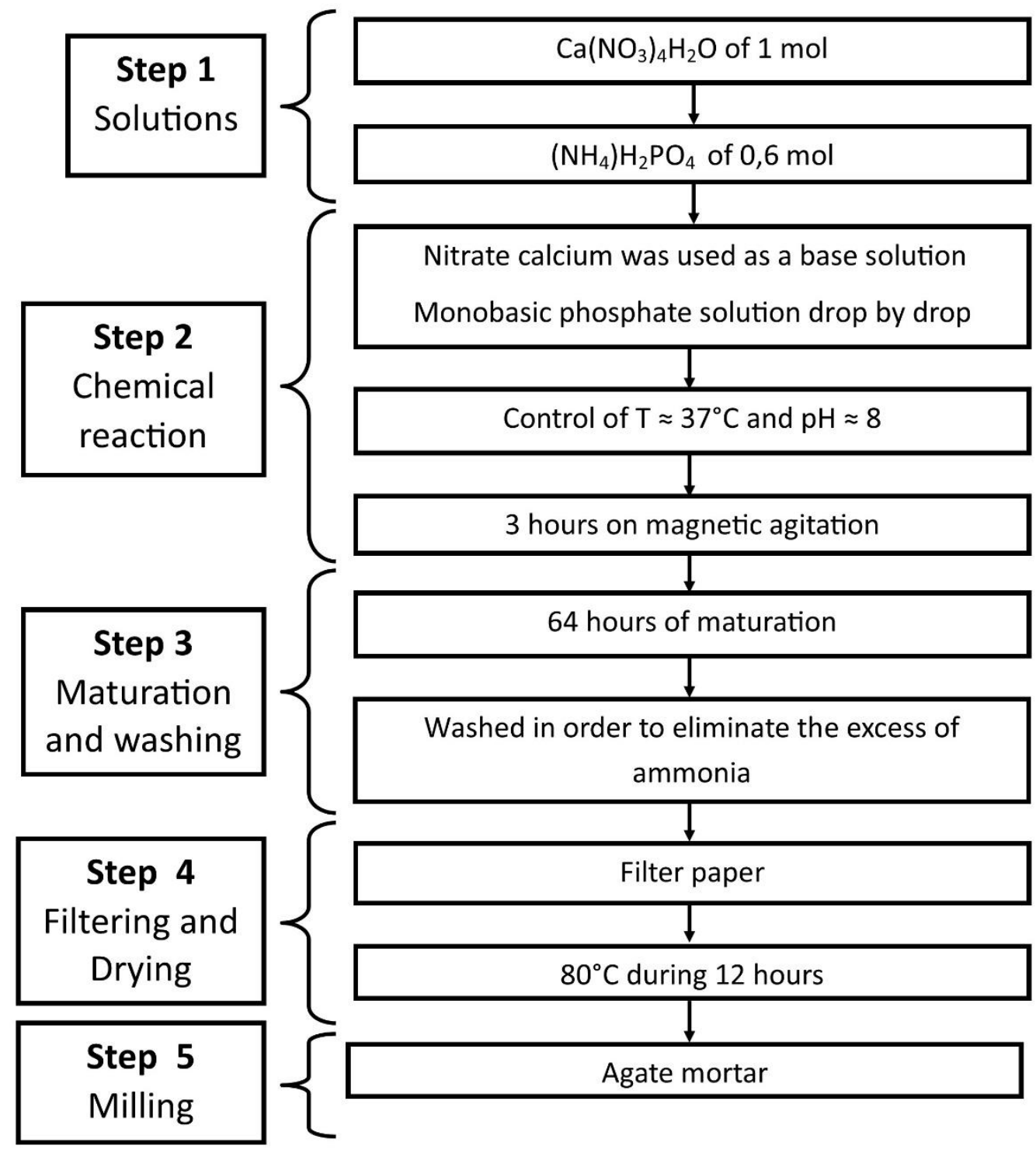

Figure 2: Scheme of the methodology used for obtaining HAp from chemical agents (synthetic method).

\subsection{Characterization of the materials}

For the XRD measures, an equipment RIGAKU, MINIFLEX II, with $\mathrm{Cu}$ anode (k $\alpha=1.5406 \AA)$, voltage of $30 \mathrm{kV}$ and resolution of $0.02^{\circ}$ in $2 \Theta$, was used. The SEM analyses were carried out using JEOL JSM-5910 LV equipment. For these studies, a coating of gold and palladium was required, since the HAp is an isolated material. EDS analyses were carried out to determine the $\mathrm{Ca} / \mathrm{P}$ relationship of the HAp powders; moreover, it was possible to determine in a qualitative way the possible presence of impurity traces. For these analyses, BRUKER equipment with an accessory of ATR platinum Diamond, was employed, with a resolution of $4 \mathrm{~cm}^{-1}$, using 32 steps in a range between 400 and $4000 \mathrm{~cm}^{-1}$. 
Table 1: List of reagents for the simulated biological fluid preparation and their ion concentration in the SBF and the blood plasma [24]

\begin{tabular}{|c|c|c|c|c|}
\hline \multirow[t]{2}{*}{ NO } & \multirow[t]{2}{*}{ CHEMICAL REAGENTS } & \multirow[b]{2}{*}{ ION } & \multicolumn{2}{|c|}{ CONCENTRATION MMOL } \\
\hline & & & $\begin{array}{l}\text { BLOOD } \\
\text { PLASMA }\end{array}$ & SBF \\
\hline 1 & $\begin{array}{l}\text { Sodium chloride } \\
{[\mathrm{NaCl}]}\end{array}$ & $\mathrm{Na}^{+}$ & 142 & 142 \\
\hline 2 & $\begin{array}{l}\text { Sodium hydrogen carbonate } \\
{[\mathrm{NaHCO} 3]}\end{array}$ & $\mathrm{HCO}^{3-}$ & 4,2 & 27 \\
\hline 3 & $\begin{array}{l}\text { Potassium Chloride } \\
{[\mathrm{KCl}]}\end{array}$ & $\mathrm{K}^{+}$ & 5 & 5 \\
\hline 4 & $\begin{array}{l}\text { Potassium Hydrogen Phosphate Trihydrate } \\
{[\mathrm{K} 2 \mathrm{HPO} 4 \cdot 3 \mathrm{H} 2 \mathrm{O}]}\end{array}$ & $\mathrm{HPO}_{4}^{2-}$ & 1,5 & 1,5 \\
\hline 5 & $\begin{array}{l}\text { Magnesium Chloride Hexahydrate } \\
{[\mathrm{MgCl} 2 \cdot 6 \mathrm{H} 2 \mathrm{O}]}\end{array}$ & $\mathrm{Mg}^{2+}$ & 2,5 & 2,5 \\
\hline 6 & Hydrogen Chloride $[\mathrm{HCl}]$ & $\mathrm{Cl}^{-}$ & 103 & 147,8 \\
\hline 7 & Calcium Chloride [CaCl2] & $\mathrm{Ca}^{2+}$ & 27 & 4,2 \\
\hline 8 & Sodium Sulfate [Na2SO4] & $\mathrm{SO}_{4}^{2-}$ & 1 & 1 \\
\hline 9 & $\begin{array}{l}\text { Tris(hydroxymethyl)aminomethane } \\
{[(\mathrm{HOCH} 2) 3 \mathrm{CNH} 2]}\end{array}$ & Buffer & 0.5 & 0.5 \\
\hline 10 & Hydrogen Chloride [HCl] & $\mathrm{Ph}$ & $7.2-7.4$ & 7.4 \\
\hline
\end{tabular}

Finally, the powders were analyzed in a simulated biological fluid (SBF) as is reported by Kokubo et al [23]. In order to apply this method, the reagents listed in table 1 were added, one by one, before incorporating the calcium chloride $\left[\mathrm{CaCl}_{2}\right]$. It is necessary to establish $\mathrm{pH}=2$ in the solution, using hydrochloric acid $[\mathrm{HCl}]$, to avoid the precipitation of the calcium phosphate in the solution. Finally, reagents 9 and 10 from the list of table 1 were added, in order to obtain a $\mathrm{pH}=7.42 \pm 0.02$.

For the bioactivity analysis, the powders were compacted, forming cylinders of $13 \mathrm{~mm}$ in diameter, employing a pressure of $100 \mathrm{MPa}$. These samples were submerged in the SBF during 0, 3, 7 and 14 days. After that, they were again analyzed using Fourier transformed infrared spectroscopy (FTIR) and scanning electron microscopy (SEM). For these analyses, a 250 Quanta model FEI SEM equipment was used. All the micrographs were obtained with a voltage of $10 \mathrm{kV}$. 


\section{RESULTS AND DISCUSSION}

\subsection{FTIR analysis}

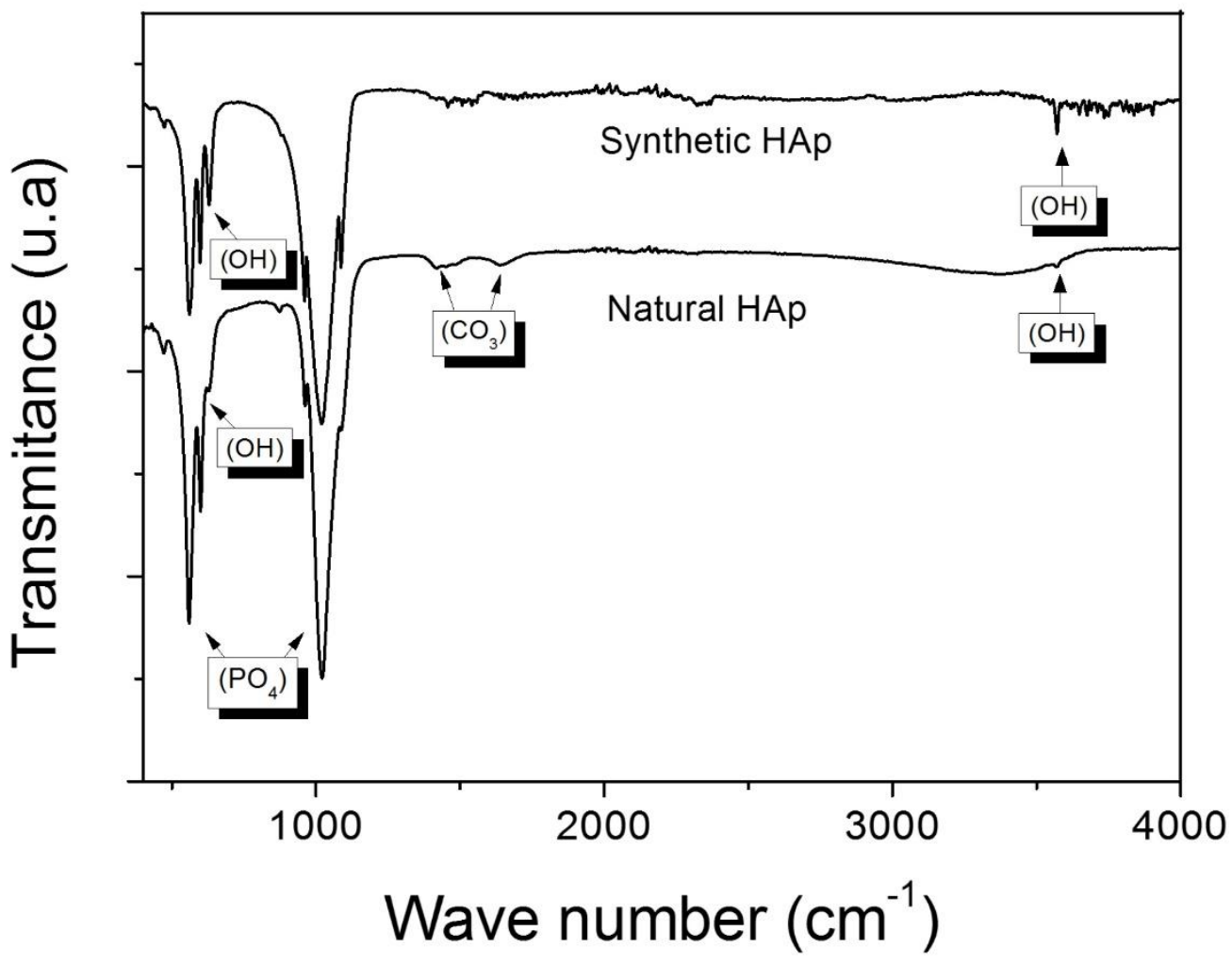

Figure 3: FT-IR spectra of natural and synthetic HAp.

Table 2: Typical vibrational bands of HAp [28]

\begin{tabular}{|c|c|c|}
\hline FUNCTIONAL GROUP & VIBRATIONAL MODE & WAVE NUMBER (CM- ${ }^{\mathbf{1}}$ ) \\
\hline \multirow{3}{*}{$\mathrm{OH}^{-}$} & Stretch & 3570 \\
\cline { 2 - 3 } & Bending & 629 \\
\hline \multirow{3}{*}{$\mathrm{PO}_{4}{ }^{3-}$} & Asymmetric bend & 561 \\
\cline { 2 - 3 } & & 598 \\
\cline { 2 - 3 } & Asymmetric stretch & 1021 \\
\cline { 2 - 3 } & & 1087 \\
\cline { 2 - 3 } & Symmetric stretch & 961 \\
\hline \multirow{2}{*}{$\mathrm{CO}_{3}{ }^{2-}$} & Asymmetric stretch & 1545 \\
\cline { 2 - 3 } & & 1450 \\
\cline { 2 - 3 } & Symetric bend & 878 \\
\hline
\end{tabular}

The FTIR technique was used to study the composition of the HAp powder. Figure 3 shows the infrared spectra of both, synthetic and natural HAp. In these spectra, bands placed at 629 and $3570 \mathrm{~cm}^{-1} \mathrm{corre}^{-}$ sponding to the hydroxyl $\left(\mathrm{OH}^{-}\right)$vibrational groups, can be identified. Furthermore, bands at 561, 598, 961, 1021 and $1087 \mathrm{~cm}^{-1}$ belonging to phosphate groups $\left(\mathrm{PO}_{4}{ }^{3-}\right)$ were found. These functional groups are charac- 
teristic of stoichiometric hydroxyapatite [1]. Moreover, table 2 presents the list of the functional groups, wavelength number and type of vibration mode.

Figure 3 shows the transmittance intensity of the bands at 629 and $357 \mathrm{~cm}^{-1}$ belonging to $\mathrm{OH}^{-}$that is lower in the case of the natural HAp compared to synthetic HAp. This difference can be attributed to the fact that synthetic HAp was obtained by means of reactions between two solutions in an aqueous environment, promoting the formation of a great quantity of this type of functional groups; on the contrary, the natural HAp was obtained using physical reactions. With this method, the organic material of bones was extracted, in order to leave only the inorganic part corresponding to different calcium phosphate, mainly the HAp. During this process, the material did not remain in contact with any aqueous solution, being the possible cause of no formation of great quantity of hydroxyl groups' type.

In figure 3, bands at 878,1450 and $1545 \mathrm{~cm}^{-1}$ corresponding to carbonate groups are identified; moreover, in table 2, the vibrational modes observed in the synthetic Hap are listed. These bands are formed, since with this methodology, a carbonate HAp was obtained. This type of HAp exhibits a substitution of carbonate ions by hydroxyl ions (A type substitution) and carbonate ions by phosphate ions (B type substitution) [27]. This type of substitutions favors the HAp powders bioactivity, because the negative charge carriers initiate and promote the bone type apatite growth in presence of the SBF [30].

\subsection{XRD analysis}

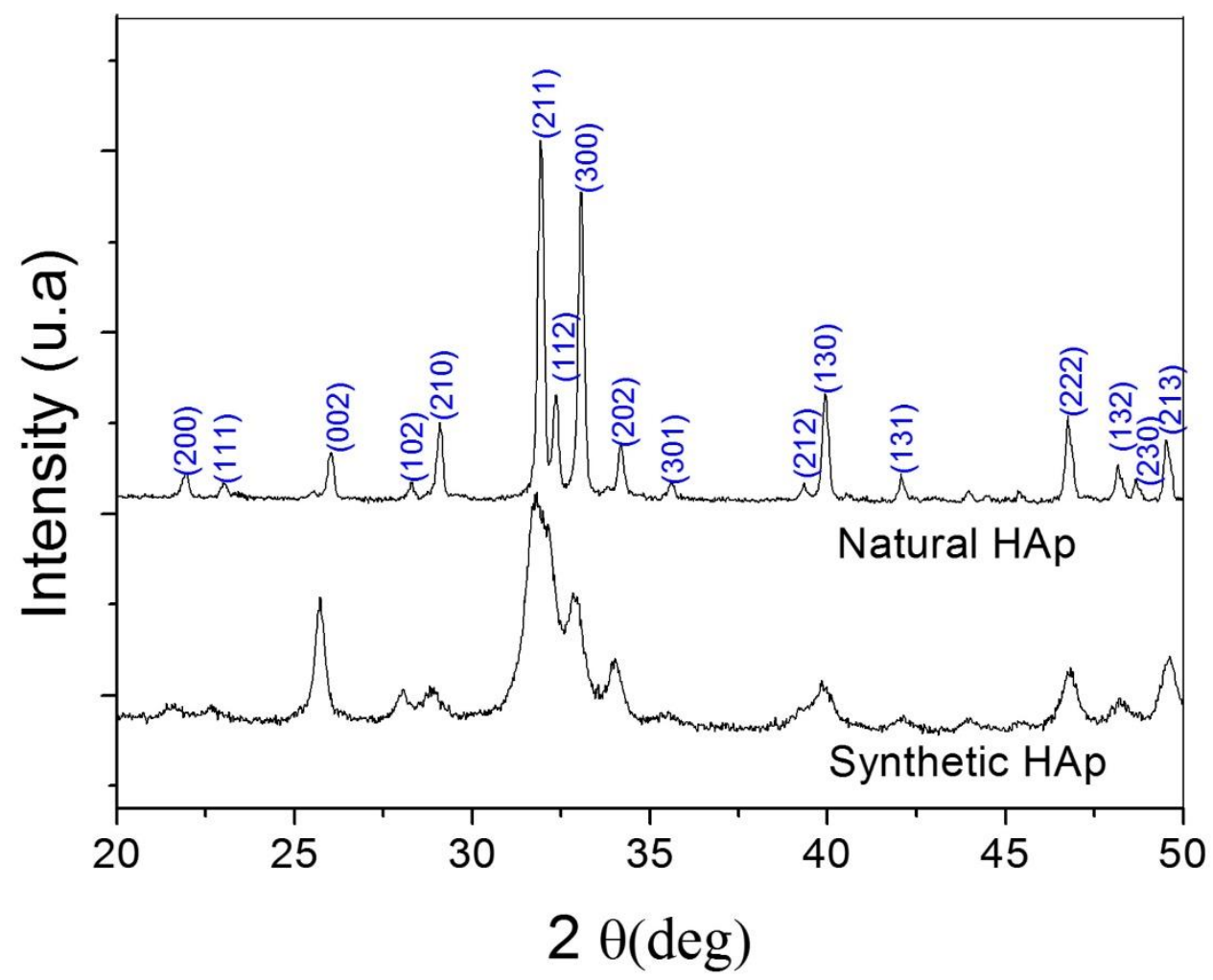

Figure 4: Diffraction patterns for natural and synthetic HAp powders

Figure 4 shows the diffraction patterns of both, natural and synthetic powders. According to this figure, the natural HAp exhibits higher crystallinity than the synthetic HAp, since its peaks present lower width than those observed in the diffractogram of synthetic HAp. The high width of the peaks belonging to synthetic HAp produces an overlapping between them, as shown at angles between $30^{\circ}<2 \theta<33^{\circ}$, where a great peak is observed; nevertheless, this peak is composed by two lines corresponding to crystalline HAp at $31.9325^{\circ}$ and $32.3470^{\circ}$. It does not matter the lower crystallinity of the synthetic HAp, in both diffraction patterns the HAp is present as a single phase; it means, that no phases corresponding to other calcium phosphate as: $\alpha$ phase calcium phosphate $(\alpha$-TCP), $\beta$-phase of tricalcium phosphate $(\beta$-TCP), tetracalcium phosphate (TTCP), 
among others, are present in the materials obtained. Therefore, it can be concluded that there is not a mixture of the HAp with other crystalline compounds; moreover, in these diffractograms, a preferential growth in the (211) plane at $2 \theta=31.9325^{\circ}$ is observed. This is a typical characteristic of the HAp.

The lattice parameters obtained for these patterns are listed in table 3 . These values are similar to those reported in the literature [2]; moreover, from the Stokes and Wilson equation, values of micro-stress were obtained as shown in table 3; it is evident that the synthetic structure undergoes a stress 6 times greater than the natural HAp. This behavior is associated to the methods employed; particularly, in the case of the chemical precipitated, the procedure was carried out at low temperatures, being in detriment of the crystalline structure, since the energy is not enough to reach the formation limit of the crystalline HAp that is $11.2 \mathrm{eV}$ [3]; then, a HAp with poor crystallinity was formed, increasing the lattice stress. The lower crystallinity and higher mocrodeformation exhibited by the synthetic HAp, compared with those observed in the natural HAp is an indicative that the first one presents the production of nanocrystals. These nanocrystals are evidenced by the formation of wide peaks in the diffraction patterns; furthermore, this type of nanocrystals can be formed by nanometric particles which sizes do not favor the bone type HAp growth when they are immersed in SBF.

Table 3: Parámetros cristalográficos obtenidos a partir de los patrones de difracción de la figura 4

\begin{tabular}{|c|c|c|c|}
\hline \multirow{2}{*}{ HYDROXYAPATITE } & \multicolumn{2}{|c|}{ LATTICE PARAMETER } & \multirow{2}{*}{ MICRODEFORMATION } \\
\cline { 2 - 3 } & $\mathrm{a}$ & $\mathrm{c}$ & \\
\hline SYNTHETIC HAP & $9.4455 \AA$ & $6.9234 \AA$ & $0.6664 \pm 0.3114$ \\
\hline NATURAL HAP & $9.3892 \AA$ & $6.8442 \AA$ & $0.1585 \pm 0.0527$ \\
\hline HAP [30] & $9.4320 \AA$ & $6.8810 \AA$ & $-\cdots$ \\
\hline
\end{tabular}

\subsection{SEM Analysis}

Figure 5 shows SEM images corresponding to both, natural and synthetic HAp at different magnifications. In these images, the grain distribution can be observed. In the case of natural HAp (figure 5(a)), grains exhibit several sizes and shapes; on the other hand, synthetic HAp particles show semi-spherical shapes, with more homogeneous sizes, as shown in figure 5(b). At a greater magnification (figure 5(c)), in the case of natural HAp, it was observed that the big grains are composed by small particles with laminar shapes, agglomerated between them; on the other hand, synthetic HAp, presents agglomeration of small grains that form a grain of higher dimension. The laminar shape exhibited by the natural HAp is attributed to the synthesis process and natural precursors [4]. The synthesis method for HAp influences not only the growth, but also the grains shape at the end of the process. Then, the size and shape of HAp nanoparticles can have influence on the bioactivity capacity of the HAp, where the nanoparticles with nanometric sizes exhibit better bioactive properties. 

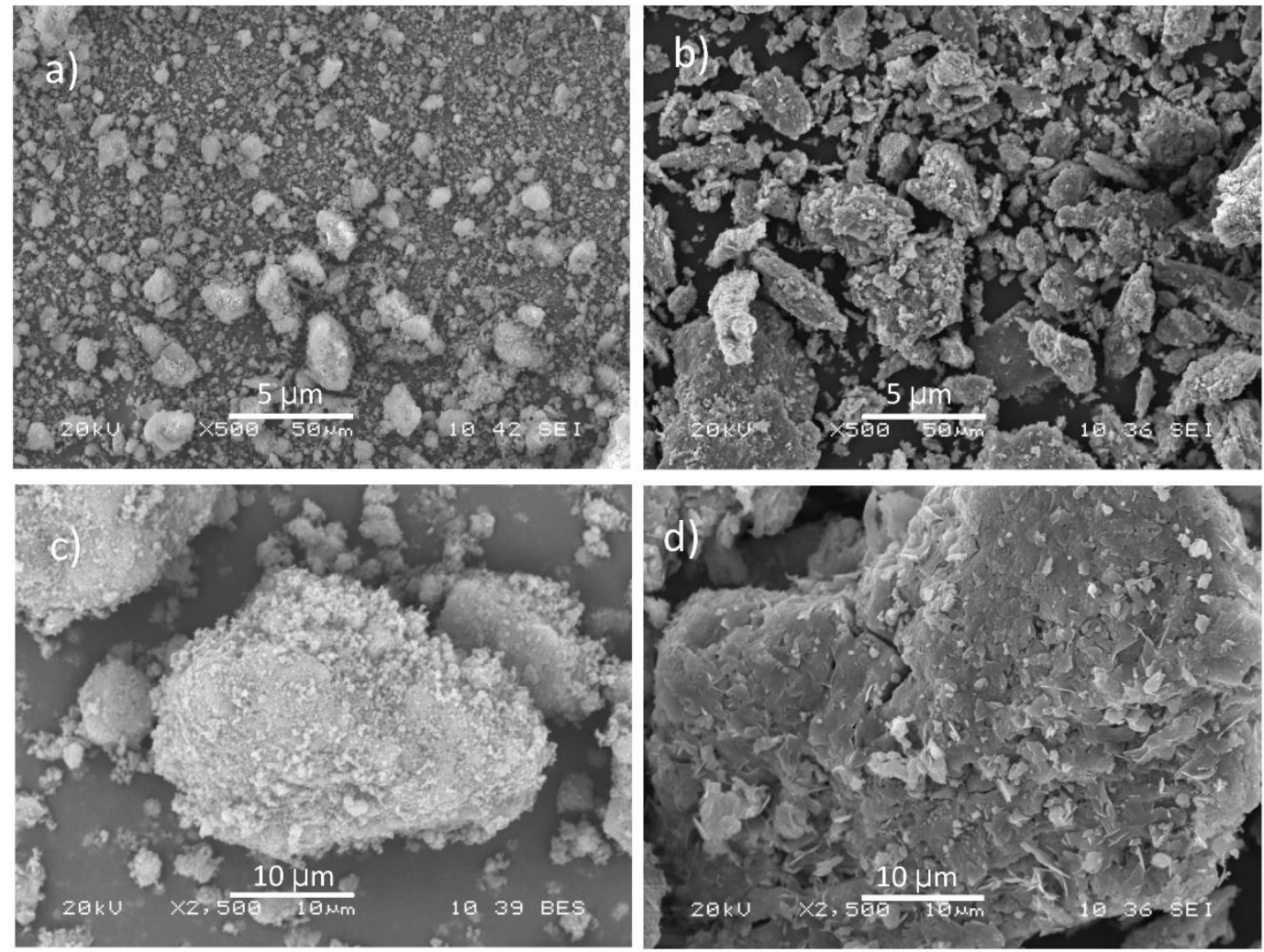

Figure 5: SEM micrographs of a) natural HAp powders at 500X, b) synthetic HAp powders at 500X c) natural HAp at $2500 \mathrm{X}$ and d) synthetic HAp at 2500X 


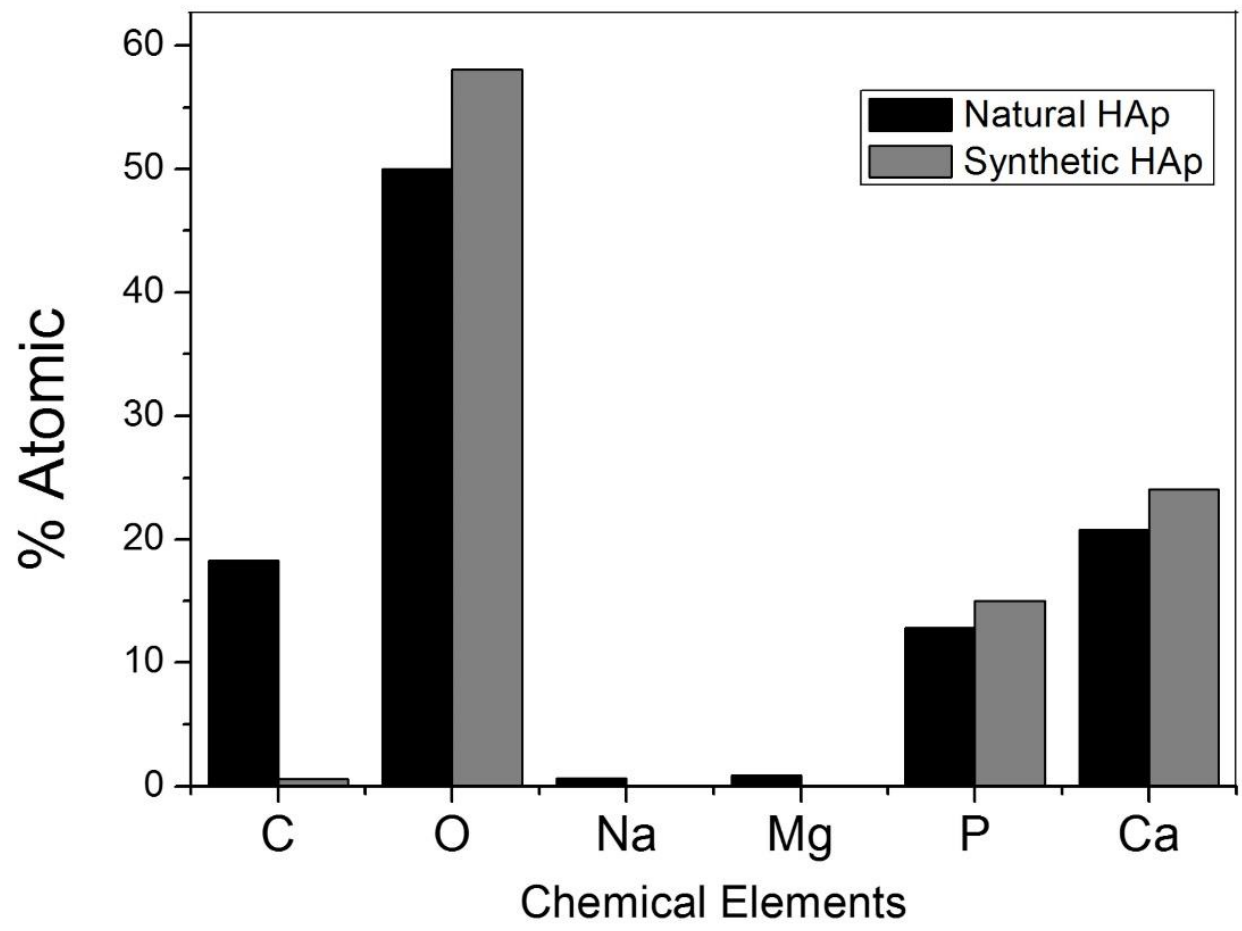

Figure 6: Atomic percentage depending on the chemical element obtained by EDS for both, natural and synthetic HAp.

In figure 6 , the atomic percentage depending on the chemical element for both natural and synthetic HAp can be observed. These results were obtained using EDS technique. According to these results, the predominant elements in both samples are $\mathrm{P}, \mathrm{Ca}$ and $\mathrm{O}$; furthermore, the spectrum of natural HAp reveals the presence of impurity traces of $\mathrm{Na}$ and $\mathrm{Mg}$. These impurities are not present in the synthetic HAp. The precedence of these impurities is attributed to the composition of the natural's Hap precursors (pig bones) [5],[6],[7]. The HAp included in the bone is not stoichiometric, since this HAp exhibits ion substitutions and impurity traces of other chemical elements presented in the HAp lattice. This kind of substitutions promotes the formation of new bone. According with this, natural HAp obtained from the porcine bone shows this type of substitutions and traces; for this reason, its bioactivity behavior can be enhanced, compared with it of the synthetic HAp [31]. 


\subsection{Bioactivity test using SBF}

\subsubsection{Fourier transform infrared spectroscopy}

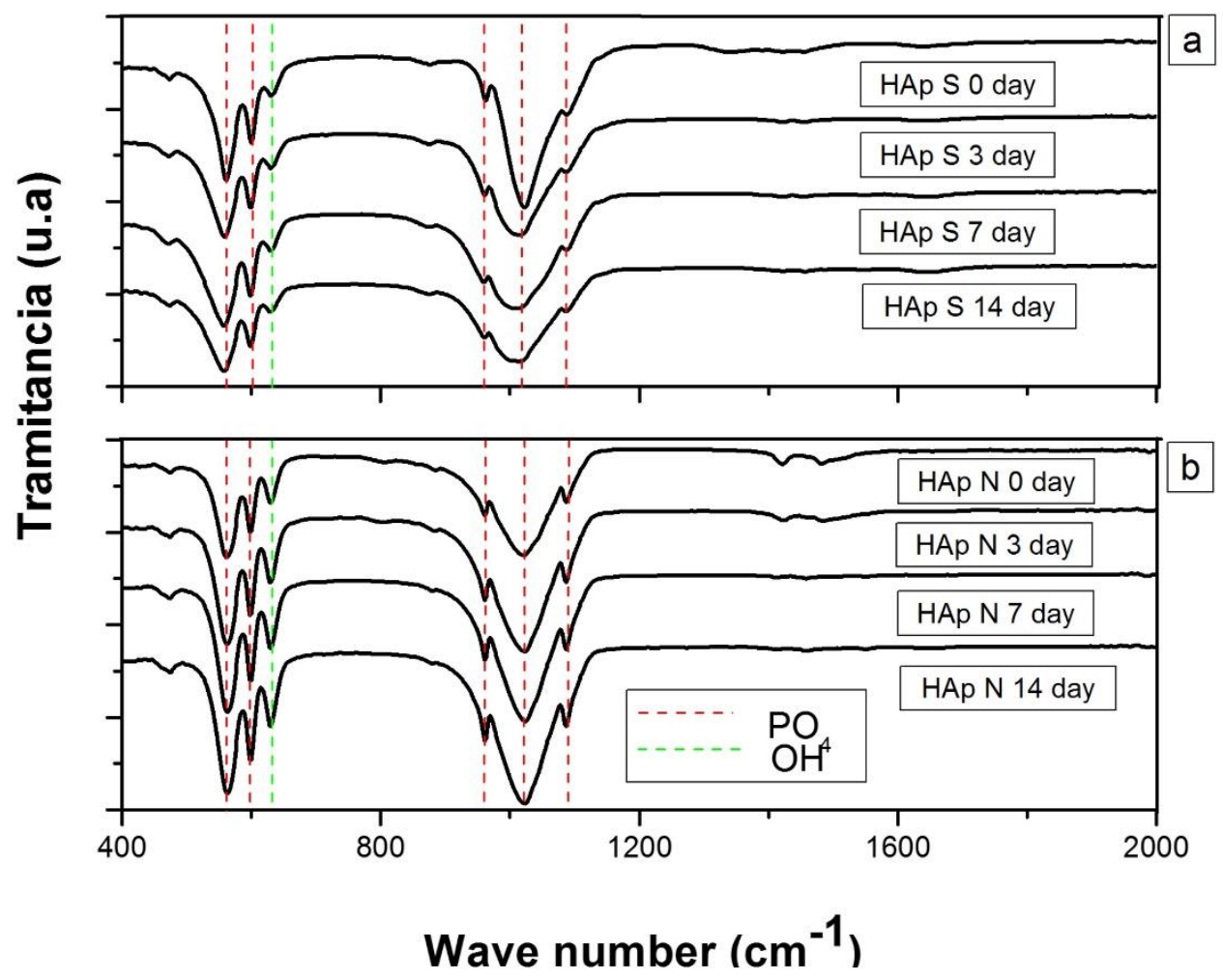

Figure 7: Infrared spectra a) set of samples of synthetic HAp submerged in SBF during 0, 3, 7 y 14 days and b) set of samples of natural HAp submerged in SBF during 0, 3, 7 y 14 days. 

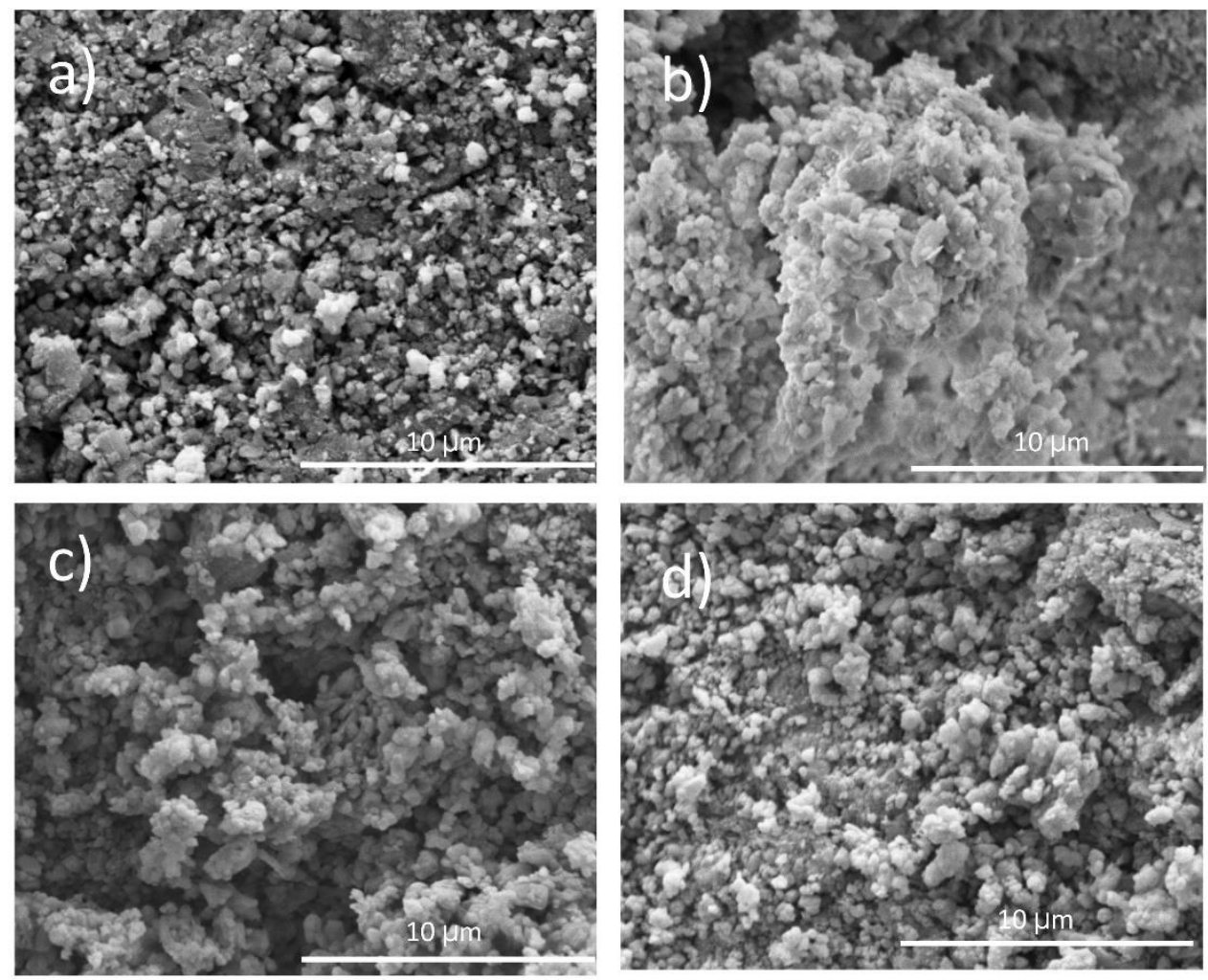

Figure 8: SEM micrographs of natural HAp submerged in SBF a) 0 days b) 3 days c) 7 days and d) 14 days 

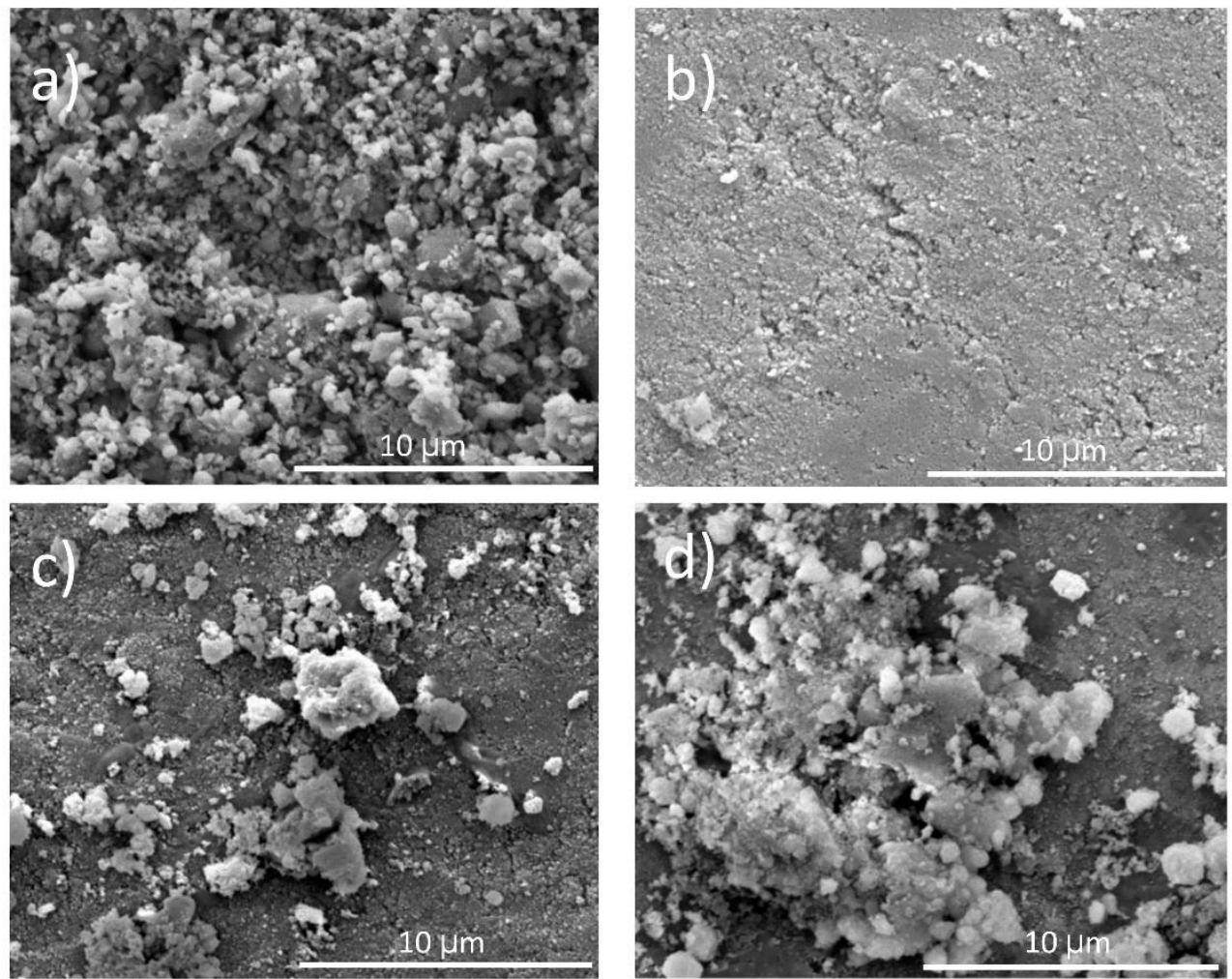

Figure 9: SEM micrographs of synthetic HAp submerged in SBF a) 0 days b) 3 days c) 7 days and d) 14 days

The $\mathrm{Ca} / \mathrm{P}$ relationship was determined from the EDS analyses and values of 1.62 and 1.59 for natural and synthetic Hap, which were obtained respectively. These values are close to the ideal value of 1.67, especially in the case of the natural HAp [3], [8]; the difference between the $\mathrm{Ca} / \mathrm{P}$ relationship for both natural and synthetic HAp, is due to the obtaining method, since the chemical precipitation was carried out at low temperatures, entailing to produce Ca deficient HAp with lower crystallinity as evidenced in XRD analysis [3].

In figure 7, the infrared spectra are presented, for different synthetic and natural samples of HAp, submerged in SBF during 0, 3, 7 y 14 days. According to figure 7, the set of samples of natural HAp (figure 7(b)) exhibits an increase in the phosphate groups, proportional to the time of immersion in SBF, compared with the set of synthetic samples (figure 7(a)) that present a decrease in the bands of the phosphate group as the time of immersion is increased. The increase in the bands intensity of the phosphate functional group is an indicative of the apatite formation on the materials surface, since as HAp is exposed to an ionic solution like SBF, it acquires a negative surface charge, that is compensated with positive ions in the solution, as Ca+. these positive ions are then counteracted with negative ions as $\mathrm{PO}_{4}{ }^{3-}$ and $\mathrm{OH}^{-}$, this ionic interaction creates a layer of amorphous calcium phosphate, that afterwards crystalizes in a new type of apatite [9]. Similarly, from figure 7, it is observed that the set of natural HAp presents a greater intensity in the $629 \mathrm{~cm}^{-1}$ band, corresponding to the hydroxyl functional group $\left[\mathrm{OH}^{-}\right]$, compared with the set of synthetic HAp. The phosphate hydroxide groups belonging to the natural HAp exhibit greater intensity, indicating high ionic activity during the time of immersion in SBF; then, a favorable growth of bone type apatite was observed, compared with the behavior shown by the synthetic HAp [10, 32, 33]. 

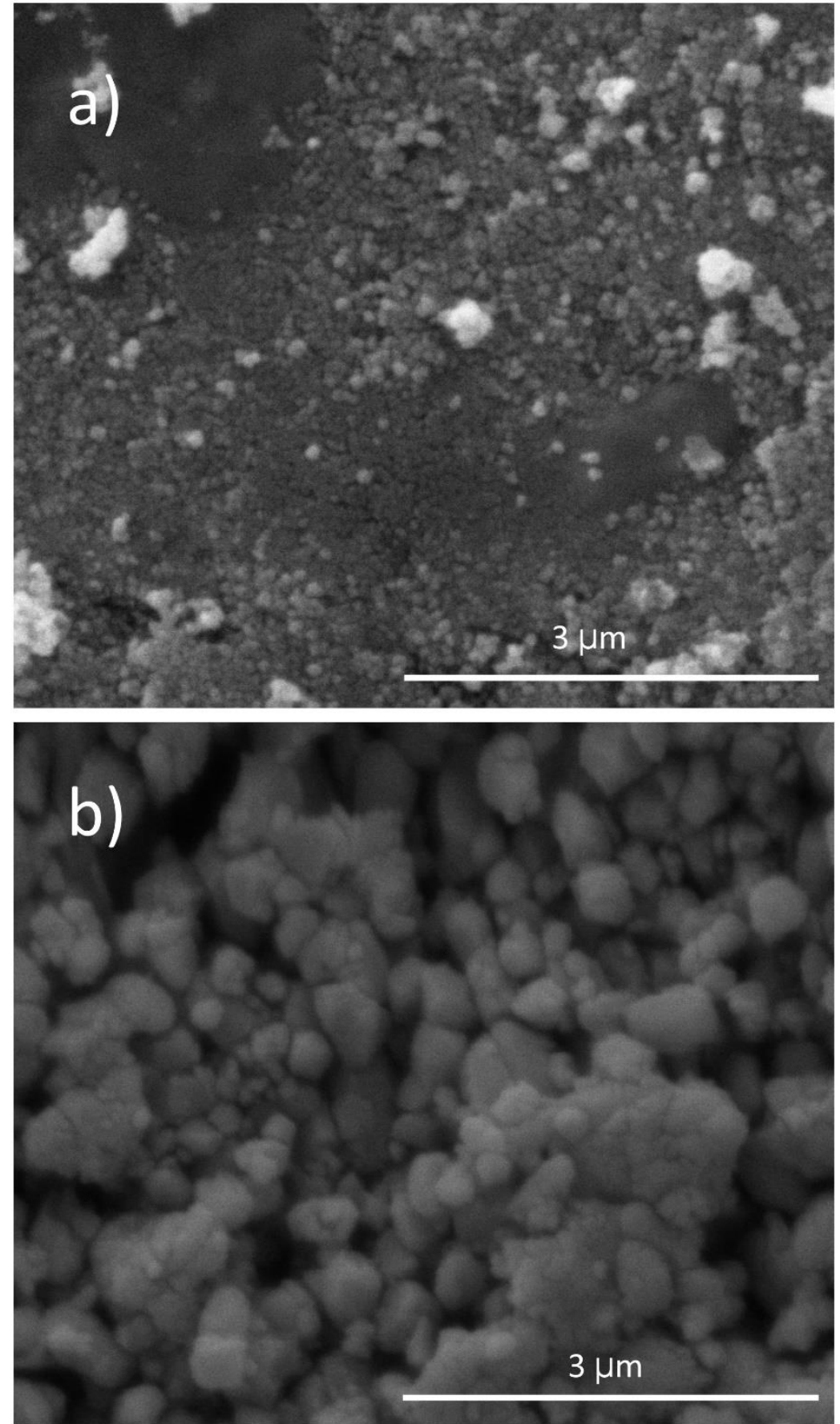

Figure 10: SEM micrographs of a) synthetic HAp submerged in SBF 14 days and b) natural HAp submerged in SBF 14 days 


\subsubsection{SEM analyses}

Figures 8 and 9 show SEM micrographs for natural and synthetic Hap, respectively submerged in SBF during 0, 3, 7 y 14 days. For the bioactivity analysis, the materials were synthesized and after that, they do not exhibit the same powders' morphology. The micrograph presented in figure 8(a) was considered the pattern sample, since it was not submerged in SBF. In this image, it is observed uniformity in the grain size and oval morphology. In figures 8(b), (c) and (d), the apatite growth exhibiting spherical shapes, can be observed. These spheres are agglomerated in order to form an interconnected lattice like ordering; the apatite formation was observed 3 days after the immersion in SBF, where the spheres formation increased with the time of immersion [11].

In figure 9(a), a similar morphology to the one presented in figure 8(a), corresponding to natural HAp is observed; nevertheless, the formation of HAp after 3 days of immersion is poor and it increases with the time of immersion; nevertheless, the growth of apatite in samples of synthetic HAp is lower than the one in natural HAp. The greater apatite growth in samples of natural HAp, is attributed to the high intensity of the $630 \mathrm{~cm}^{-1}$ band, corresponding to the flexion vibration type of the $\mathrm{OH}^{-}$functional group, in this set of samples, this growth is observable in IR spectra shown in figures 3 and 7. [10].

The increase in the bioactivity is promoted by the combination of different calcium phosphate phases. Powders obtained from pig bones are a combination of hydroxyapatite and tricalcium phosphate. This combination improves the bioactivity with respect to pure HAp [34].

Figure 10 shows SEM micrographs at 50000X for natural and synthetic hydroxyapatite, immersed in SBF during 14 days. Synthetic HAp exhibits grains of nanometric sizes (fig. 10.a); these sizes are similar to those present in the bone. Therefore, natural HAp (fig. 10.b) shows grains of micrometric sizes. The micrometric grains promoted a greater growth of the apatite bonelike than it promoted by nanometric grains.

Finally, it can be highlighted that in this work, we performed a comparative study of the bioactivity exhibited by both, natural and synthetic HAp, and this study was carried out using two complementary techniques as FTIR and SEM; furthermore, it was observed the great relevance that the particle size exerts on the bioactivity and the chemical response of these materials, by means of the intensity of the functional groups of the hydroxyl phosphates.

\section{CONCLUSIONS}

Powders of natural and synthetic HAp were obtained by using new methods proposed. It was found that natural HAp exhibited better structural properties compared with synthetic HAp. On the other hand, XRD analysis allowed us to observe that both, natural and synthetic HAp exhibit a single phase that is in agreement with the reposts; furthermore, the natural HAp presented higher crystallinity than the synthetic HAp. From the FTIR results, typical functional groups of stoichiometric HAp were identified, evidencing that both methods are successfully obtaining crystalline HAp. Finally, SEM results indicated that the morphology of the materials is strongly influenced by the method type, since natural HAp exhibited laminar shapes that were no observed in synthetic HAp. Similar to the case of bioactivity, it was evidenced a great increase of the $\mathrm{OH}-$ and PO43- functional groups for the set of natural HAp samples that indicates the formation of apatite. Using SEM analysis, it was identified a formation of an apatite layer on the surface of HAp samples; furthermore, this layer of apatite exhibited a greater growth in samples obtained by the natural method.

\section{ACKNOWLEDGMENTS}

The authors gratefully acknowledge financial support from the Dirección Nacional de Investigaciones of the National University.

\section{BIBLIOGRAPHY}

[1] RAYA I., MAYASARI E., YAHYA A., et al., "Shynthesis and Characterizations of Calcium Hydroxyapatite Derived from Crabs Shells (Portunus pelagicus) and Its Potency in Safeguard against to Dental Demineralizations”, International Journal of Biomaterials, v. 2015, pp. 469176, Feb. 2015.

[2] ZHOU, H., LEE, J., "Nanoscale hydroxyapatite particles for bone tissue engineering", Acta Biomateralia., v. 7, n. 7, pp. 2769-2781, Jul. 2011.

[3] MilOVAC, D., GALLEGO FERRER, G., IVANKOVIC, M., et al., "PCL-coated hydroxyapatite scaffold derived from cuttlefish bone: morphology, mechanical properties and bioactivity", Materials Science and Engineering: C, v. 34, n. 1, pp. 437-445, jan. 2014. 
[4] DE JONG W.F., "Le substance minerale dans le os”, Recueil des Travaux Chimiques des Pays-Bas, v. 45 , n. 6, pp. 445-448, Apr. 1926.

[5] POSNER A.S. "Crystal chemistry of bone mineral", Physiological. Reviews., v. 49, n. 4, pp. 760-792, Oct. 1969.

[6] POSNER A.S., PERLOFF A., DIORIO A.F., "Refinement of the hydroxyapatite structure", Acta Crystallographica., v. 11, pp. 308-309, Dec. 1958.

[7] KAY, M.I., YOUNG R.A., POSNER A.S., "Crystal structure of hydroxyapatite”, International journal of science nature, v. 204, pp. 1050-1052, Dec. 1964.

[8] HUANG Y.-C., HSIAO P.-C., CHAI H.-J., "Hydroxyapatite extracted from fish scale: Effects on MG63 osteoblast-like cells", Ceramics International. v. 37, m. 6, pp. 1825-1831, Aug. 2011.

[9] SADAT-SHOJAI, M., KHORASANI, M.T., DINPANAH-KHOSHDARGI, E., et al., "Synthesis methods for nanosized hydroxyapatite with diverse structures", Acta Biomaterialia, v. 9, n. 8, pp. 7591-7621, Aug. 2013.

[10] ZHANG G., CHEN J., YANG S., et al., "Preparation of amino-acidregulated hydroxyapatite particles by hydrothermal method", Materials. Letters, v. 65, n. 3, pp. 572-574, Feb. 2011.

[11] JOKIC, B., MITRIC, M., RADMILOVIC, V., et al., "Synthesis and characterization of monetite and hydroxyapatite whiskers obtained by a hydrothermal method", Ceramics International., v. 37, n. 1, pp. 167173, Jan. 2011.

[12] STIPNIECE, L., SALMA-ANCANE, K., BORODAJENKO, N., et al., "Characterization of Mgsubstituted hydroxyapatite synthesized by wet chemical method", Ceramics. International., v. 40, n. 2, pp. 3261-3267, Mar. 2014.

[13] KIM D.W., CHO I.-S., KIM J.Y., et al., "Simple large-scale synthesis of hydroxyapatite nanoparticles: in situ observation of crystallization process", Langmuir, v. 26, n. 1, pp. 384-388, Oct. 2010.

[14] DHANG V., RHEE K.Y., PARK S.-J., "The facile and low temperature synthesis of nanophase hydroxyapatite crystals using wet chemistry", Materials Science and Engineering: C, v. 36, pp. 152-159, Mar. 2014.

[15] KAMALANATHAN P., RAMESH S., MANG L.T., et al., "Synthesis and sintering of hydroxyapatite derived from eggshells as a calcium precursor”, Ceramics International., v. 40, n. 10B, pp. 16349-16359, Dec. 2014.

[16] MUCALO M.R., 14 - Animal-bone derived hydroxyapatite in biomedical applications in: Hydroxyapatite Biomed. Appl., The University of Waikato, 1 ed, New Zealand, 2015

[17] AKRAM, M., AHMED, R., SHAKIR, I., et al., "Extracting hydroxyapatite and its precursors from natural resources", Journal of Materials Science. v. 49, n. 4, pp. 1461-1475, Feb. 2014.

[18] MONDAL, S., MONDAL, B., DEY, A., et al., "Studies on processing and characterization of hydroxyapatite biomaterials from different bio wastes", Journal of Minerals and Materials Characterization and Engineering v. 11, n. 1, pp. 55-67, Jan. 2012.

[19] HABERKO, K., BUCKO, M.M., BRZEZINSKA-MIECZNIK, J., et al., "Natural hydroxyapatite-its behaviour during heat treatment”, Journal of the European Ceramic Society., v. 26, n. 4-5, pp. 537-542, Aug. 2005.

[20] JANUS, A.M., FARYNA, M., HABER,KO K., et al., "Chemical and microstructural characterization of natural hydroxyapatite derived from pig bones”, Microchimica Acta., v. 161, n. 3-4, pp. 349-353, Jun. 2008.

[21] KIM S.-H., SHIN J.-W., PARK S.-A., et al., "Chemical, structural properties, and osteoconductive effectiveness of bone block derived from porcine cancellous bone", Journal of Biomedical Materials Research Part B: Applied Biomaterials., v. 68, n. 1, pp. 69-74, Nov. 2004.

[22] SOBCZAK-KUPIEC, A., WZOREK, Z., "The influence of calcination parameters on free calcium oxide content in natural hydroxyapatite", Ceramics International. v. 38, n. 1, pp. 641-647, Jan. 2012.

[23] KOKUBO, T., TAKADAMA, H., "How useful is SBF in predicting in vivo bone bioactivity?", Biomaterials., v. 27, n. 15, pp. 2907-2915, May. 2006.

[24] KOKUBO, T., "Bioactive glass ceramics: properties and applications", Biomaterials., v. 12, n. 2, pp. 155-163, Mar. 1991.

[25] HESARAKI, S., NAZARIAN, H., POURBAGUI-MASOULEH, M., et al., "Comparative study of mesenchymal stem cells osteogenic differentiation on low-temperature biomineralized nanocrystalline carbonated hydroxyapatite and sintered hydroxyapatite", Journal of biomedical materials research. Part B Appl. Bi- 
omater., v. 102, n. 1, pp. 108-118, Jan. 2014.

[26] BARAKAT, N.A.M., KHIL, M.S., OMRAN, A.M., et al., "Extraction of pure natural hydroxyapatite from the bovine bones bio waste by three different methods", Journal of Materials Processing Technology., v. 209, n. 7, pp. 3408-3415, Apr. 2009.

[27] HENCH L.L, "Bioceramics: From Concept to Clinic", Journal of the American Ceramic Society., v. 74, n. 7, 1487-1510, Jul. 1991.

[28] BIENENSTOCK A., POSNER A.S., "Calculation of the x-ray intensities from arrays of small crystallites of hydroxyapatite”, Archives of Biochemistry and Biophysics. v. 124, pp. 604-607, Dec. 1964.

[29] KOKUBO, T., Bioceramics and their clinical applications. Woodhead Pub. and Maney Pub. on behalf of Institute of Materials, 1 ed, Minerals \& Mining, 2008.

[30] LIU Y., SHEN Z., "Dehydroxylation of Hydroxyapatite in Dense Bulk Ceramics Sintered by Spark Plasma Sintering”, Journal of the European Ceramic Society., v. 32, pp. 2691-2696, Aug. 2012.

[31] GIRALDO-BETANCUR A. L, ESPINOSA-ARBELAEZ D. G, DEL REAL-LOPEZ A, et al., "Comparison of physicochemical properties of bio and commercial hydroxyapatite", Current Applied Physics., v. 13, n. 7, pp. 1383-1390, Sep. 2013.

[32] HAHN, B. D, LEE, J. M, PARK, D. S, et al., "Enhanced bioactivity and biocompatibility of nanostructured hydroxyapatite coating by hydrothermal annealing", Thin Solid Films, v. 519, n. 22, pp. 8085-8090, Sep. 2011.

[33] KONG, L., GAO, Y., LU, G., et al., "A study on the bioactivity of chitosan/nano-hydroxyapatite composite scaffolds for bone tissue engineering”, European Polymer Journal., v. 42, n. 12, pp. 3171-3179, Dec. 2006.

[34] FARZADI, A., SOLATI-HASHJIN, M., BAKHSI F, et al., "Synthesis and characterization of hydroxyapatite/ $\beta$-tricalcium phosphate nanocomposites using microwave irradiation”, Ceramics International., v. 37, n. 1, pp. 65-71, Jan. 2011. 